\title{
A Study of the Diurnal Height Changes Among Sample of Adults Aged Thirty Years and above in Ghana
}

\author{
Frederick Vuvor*, Obed Harrison \\ Department of Nutrition and Food Science, School of Biological Sciences, College of Basic and Applied \\ Sciences, University of Ghana, P. O. Box LG 134, Legon-Accra, Ghana
}

*Corresponding Author: Frederick Vuvor, Department of Nutrition and Food Science, School of Biological Sciences College of Basic and Applied Sciences, University of Ghana, Ghana, Email: fredvuvor@yahoo.com

\begin{abstract}
Introduction: The diurnal variations in stature significantly affect the reliability of height data. Diurnal variation in stature affects the reliability of any data that involves height measurement without a correction factor at different times of the day. The aim of the study was to determine the diurnal height loss of adults aged $\geq$ thirty years in the Greater Accra Region of Ghana.
\end{abstract}

Materials and Methods: A total of 90 subjects were randomly sampled. Weight and Height measurements were taken twice a day between 5.30-7.30am and 5-7pm. WHO-Step wise questionnaires were used to gather all information on subjects.

Results: The maximum height loss between $7 \mathrm{am}$ and $7 \mathrm{pm}$ from the study was $2.7 \mathrm{~cm}$ whiles mean was 1.61 $\mathrm{cm}$. There was a greater mean height loss in males $(1.63 \mathrm{~cm})$ than in females $(1.59 \mathrm{~cm})$, greater mean BMI difference between morning and evening BMI was observed for females $\left(1.21 \mathrm{~kg} / \mathrm{m}^{2}\right)$ than in males $(1.02$ $\mathrm{kg} / \mathrm{m}^{2}$ ). There was significant association between height loss and occupational activities ( $p$-value $<0.001$ ). Conclusion: The height of the subjects significantly reduced from $7 \mathrm{am}$ to $7 \mathrm{pm}$ and increased from $7 \mathrm{pm}$ to 7am. The major factor that contributes to diurnal height variations is the level of occupational activity performed in a day. No significant relationships were established between age, sex, total caloric intake and diurnal height loss.

Keywords: Diurnal Height Variations, Anthropometry, BMI, Intervertebral Disc.

\section{INTRODUCTION}

Height of a person can be defined as the distance from the base of the foot (sole) to the top of the head. Anatomically, it is the composite of linear dimension of the roof or the maximum protuberance of the skull, vertebral column, pelvis and the end of the lower limbs. It is the most predominantly used anthropometric indices. It has been employed in various fields of study and professions including, medicine in the study of height loss due to aging and many disorders such as scoliosis, knock-knees, hyper extended knees, bowlegs and knee flexures in osteoporotic, spinal fracture studies and in anthropometry. It is important in ergonomics concerned with fitting people, their technological tools and environments(Krishan \& Vij, 2007) (Sorkin, Muller, \& Andres, 1999) (Briot, Legrand, Pouchain, Monnier, \& Roux,
2010)(Berecki-Gisolf, Spallek, Hockey, \& Dobson, 2010).

It is usually assumed that any measurement at any time of height gives people sufficient information for whichever purpose it is taken for. However, there is systematic change in height with respect to time of the day which introduces errors usually regarded by many as so small that can be safely ignored. On the contrary, diurnal variations in stature significantly affect the reliability of its use in different fields of discipline. There is a need to minimize measurement error of height in the assessment. Within the course of a day the types of activity may affect decline in height of an individual (Buckler, 1978)(Krishan \& Vij, 2007).

A study reported percentages pertaining to length of the body that is dominated by the 
spinal column as $33.33 \%$ and of this, $30 \%$ comprises the intervertebral discs(Eston \& Reilly, 2013). The greatest loss in height has been isolated to the region of the lumbar vertebra which possesses the thickest intervertebral discs in the spine (Karakida, Ueda, Ueda, \& Miyasaka, 2003). Collagen and proteoglycans are the major macromolecular constituents of the nucleus pulposus of the intervertebral discs, which consists of a network of collagen fibers embedded in a proteoglycans gel(Park, 1997). The nucleus pulposus gel consists of $80-90 \%$ water. It is variable and represents equilibrium between the mechanical pressure which dehydrates the gel, and the swelling pressure of the hydrophilic proteoglycans, which causes the gel to absorb fluid. The mechanical pressure occurs during the day due to factors such as the Body Mass Index (BMI) of the individual, gravitational force, occupational exposures and activity which introduce forms of load on the body (Rodacki, Fowler, Provensi, Rodacki, \& Dezan, 2005)(Ismaila \& Charles-Owaba, 2008). Fluid is expelled from the nucleus pulposus of the intervertebral discs, which leads to the decrease in stature(Adams, Dolan, Hutton, \& Porter, 1990). This was confirmed that the amount of height loss is proportional to the amount of fluid loss and degree of compressive loads on the spine (Francis Smith \& Hadjipavlou, 2004). The swelling pressure on the other hand occurs during recumbence of sleep or when one is in a supine position, where the loading of intervertebral discs are significantly reduced, resulting in them absorbing fluid, increasing in volume and subsequently, increasing the total stature of an individual (Adams et al., 1990). The diurnal variations in the discs indicate water can be squeezed out under pressure and compressive load when it exceeds the osmotic pressure of the discal tissue leading to expulsion of fluid respectively (WHITE III \& Gordon, 1982)(Dowzer, Reilly, \& Cable, 1998).

\section{RESULTS}

\subsection{Background Information}

Table1: Background Information on age and sex

\begin{tabular}{|l|l|l|}
\hline \multicolumn{1}{|c|}{ Parameters } & \multicolumn{1}{c|}{ Frequency (n) } & \\
\hline Age Group Distribution (Years) & 15 & 16.7 \\
\hline $30-35$ & 15 & 16.7 \\
\hline $36-40$ & 16 & 17.8 \\
\hline $41-45$ & 14 & 15.6 \\
\hline $46-50$ & $14)$ \\
\hline
\end{tabular}

Studies have shown that about $1.0 \mathrm{~cm}$ to $3.0 \mathrm{~cm}$ loss in stature of an individual is due to $9.9 \%$ to $20.0 \%$ decrease in vertebral column height. Stature loss is also thought to occur in the joints of the pelvis, knee and ankle. Height is expected to be at its maximum after rising from bed. Diurnal variations in stature may substantially affect the reliability of height data at different times of the day (Park, 1997)(Krishan \& Vij, 2007)(Voss \& Bailey, 1997)(Siklar, Sanli, Dallar, \& Tanyer, 2005) .

Due to the increasing use of height in the estimation of nutritional, health status, ergonomic and medico-legal quantitative measures of individuals, there is the need to standardize the height measurement and BMI of an individual taking into account the diurnal changes in height. This study considered diurnal loss in heights for effective analysis, interpretation and use.

\section{MATERIALS ANd MethodS}

\section{Study Design and Population}

The experimental sample consisted of randomly selected individuals of both genders classes from the six different districts in the Greater Accra Region. The weight and height of each subject was measured in the morning (5.30 am to $7.30 \mathrm{am}$ ), and in the evening (5 pm to $7 \mathrm{pm}$ ). The measurements were taken in triplicates using standard techniques. An interview administered questionnaires were used to gather all information on the subjects.

The eligible subjects were apparently healthy, free from any ailment and deformity; aged30 years and above; not pregnant or lactating and willing to take part in the experimental study at those times $(5.30 \mathrm{am}-7.30 \mathrm{am}$ and $5 \mathrm{pm}-7 \mathrm{pm})$ of the day. The height of an individual rapidly begins to decrease within the first two hours after rising from bed (Krishan \& Vij, 2007). The average Ghanaian is usually awake and ready by 6 am and is usually closed from work by $5 \mathrm{pm}$. These made it convenient time for the willing subjects to participate in the study. 


\begin{tabular}{|l|l|l|}
\hline $51-55$ & 8 & 8.9 \\
\hline $56-60$ & 9 & 10.0 \\
\hline $61-65$ & 10 & 11.1 \\
\hline $66-70$ & 3 & 3.3 \\
\hline Sex Distribution & \multicolumn{2}{l|}{} \\
\hline Male & 52 & 57.8 \\
\hline Female & 38 & 42.2 \\
\hline Total & 90 & 100.0 \\
\hline
\end{tabular}

The results showed majority of the respondents was in the $66-70$ years age respondents were in the age group of $30-\quad$ group of the 90 respondents interviewed, 50 years $(66.8 \%)$. The least proportion of $57.8 \%$ comprised of males.

\subsection{Diet and Eating Habits}

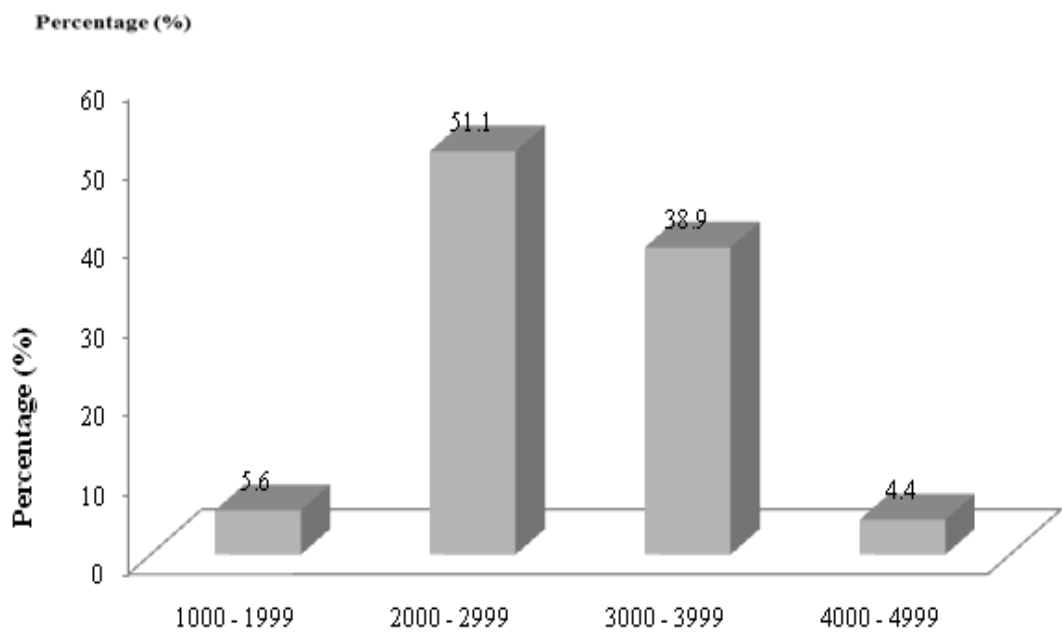

Total Calo ric Intake

Fig1: Distribution of Subjects by their Total Caloric Intake (kcal)/day

An assessment of the total caloric intake per day revealed that, majority of the subjects (51.1\%) had caloric intakes between 2000 -

\subsection{Anthropometric Data}

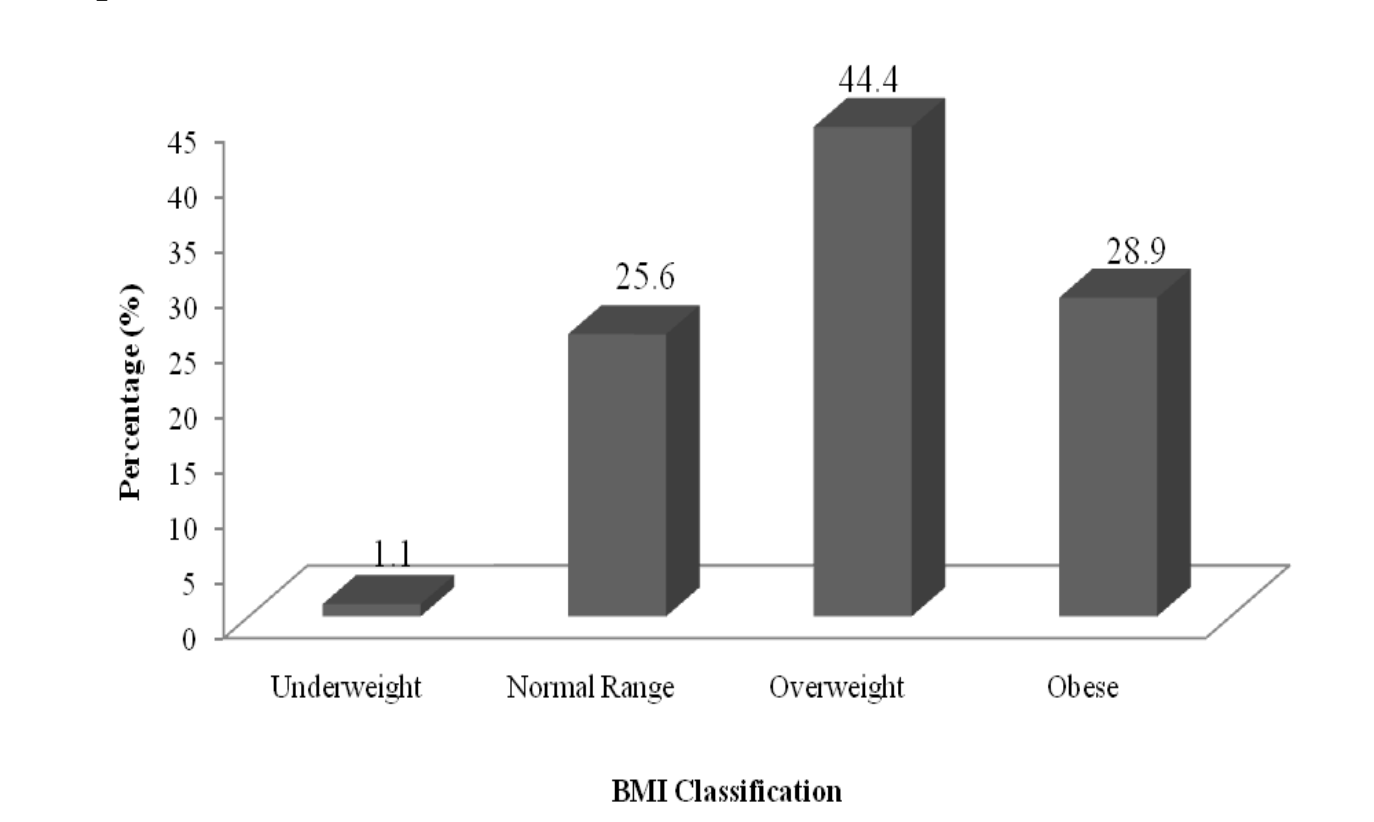

BMI Classification
2999 kilocalories during the day of data collection.

Fig2: Body Mass Index Profile of Subjects 
The BMI classification used was as employed by the (Barba, Cavalli-Sforza, Cutter, \& Darnton-Hill, 2004). 44.4\% of the respondents were observed to be overweight whiles to $28.9 \%$ were obese. Only $1.1 \%$ of the subjects were found to be underweight.

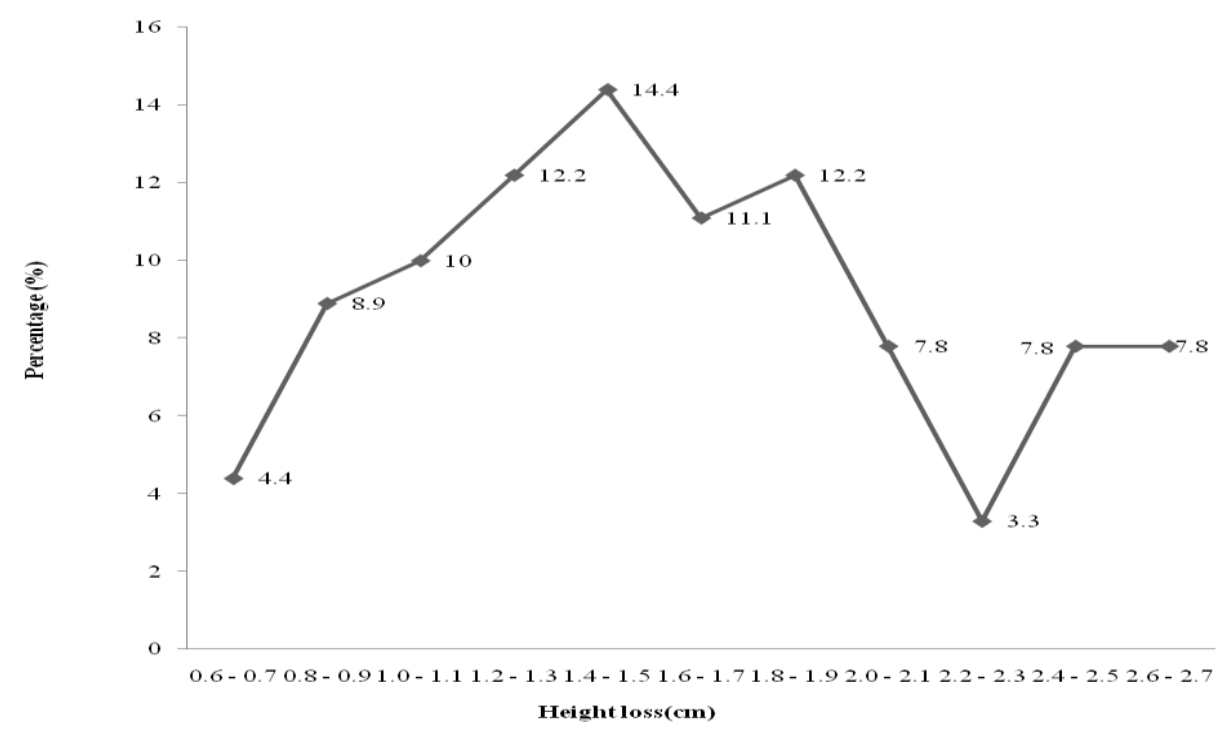

Fig3: Height Loss by Subjects between Morning and Evening

The most height loss by the subjects after the morning and evening measurements of stature was between the values of $1.4 \mathrm{~cm}-1.5 \mathrm{~cm}$ Table2: Descriptive Statistics for Weight, Height and BMI
$(14.4 \%)$. The least proportion of height loss (3.3\%) was recorded for $2.2 \mathrm{~cm}-2.3 \mathrm{~cm}$.

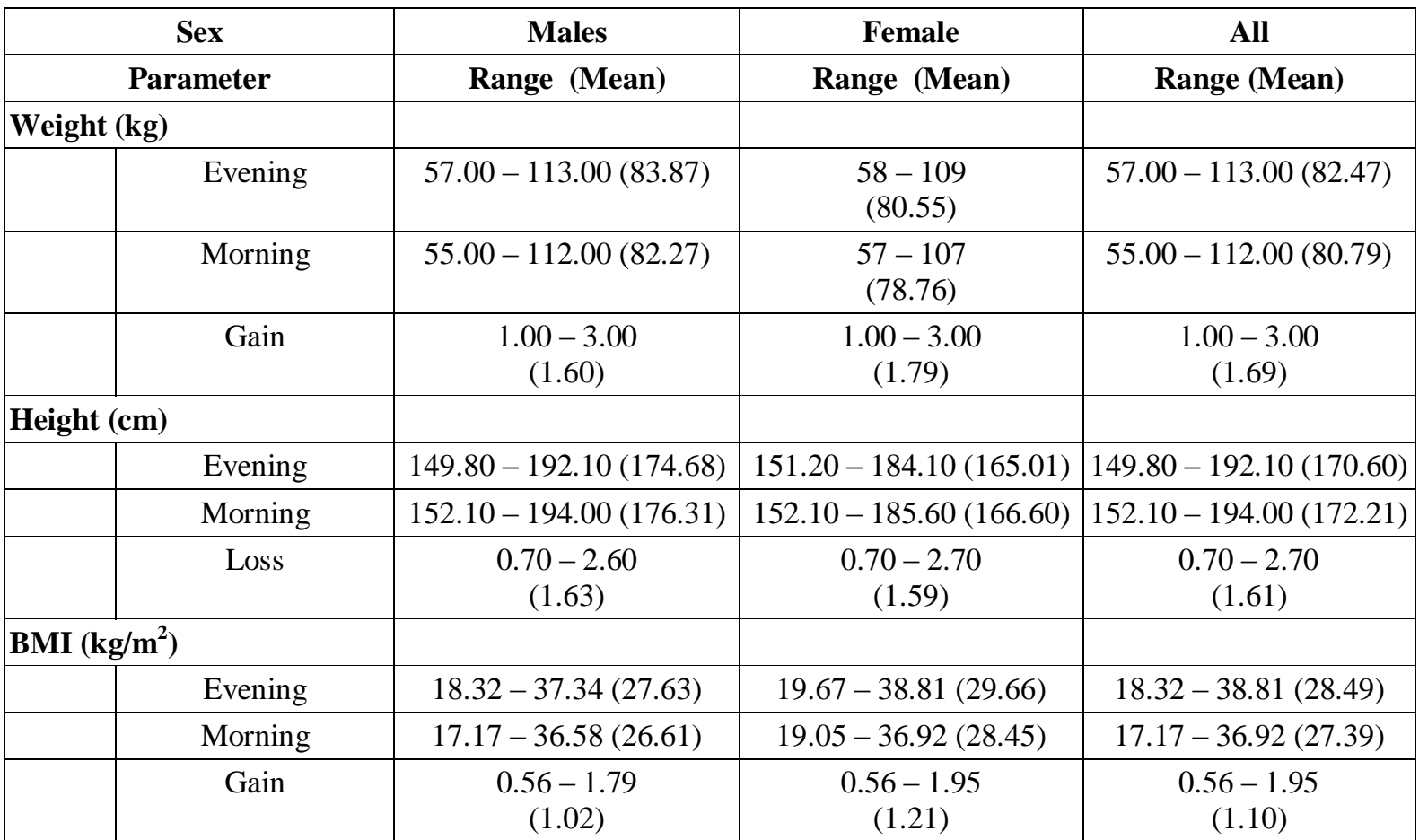

The mean morning and evening heights of the males were $174.68 \mathrm{~cm}$ and $176.31 \mathrm{~cm}$ respectively and resulted in a mean height loss of $1.63 \mathrm{~cm}$. The morning and evening heights ranged from $149.80 \mathrm{~cm}-192.10 \mathrm{~cm}$ and 152.10 $\mathrm{cm}-194.00 \mathrm{~cm}$ respectively, whiles the losses in height ranged from $0.70 \mathrm{~cm}$ to $2.60 \mathrm{~cm}$. The weight gain ranged from $1.00-3.00 \mathrm{~kg}$. The calculated BMI for males in the morning differed from that of the evening by values that ranged from 0.56 to $1.79 \mathrm{~kg} / \mathrm{m}^{2}$. The females however recorded mean morning and evening heights of $166.60 \mathrm{~cm}$ and $165.01 \mathrm{~cm}$ respectively and that resulted in a mean height loss of $1.59 \mathrm{~cm}$. Whiles the morning height ranged from $151.20 \mathrm{~cm}-184.1 \mathrm{~cm}$, the evening 
height ranged from $152.10 \mathrm{~cm}-185.60 \mathrm{~cm}$. The losses in height ranged from $0.70 \mathrm{~cm}$ to $2.70 \mathrm{~cm}$. The calculated BMI for the morning differed

from that of the evening by values that ranged from 0.56 to $1.95 \mathrm{~kg} / \mathrm{m}^{2}$.

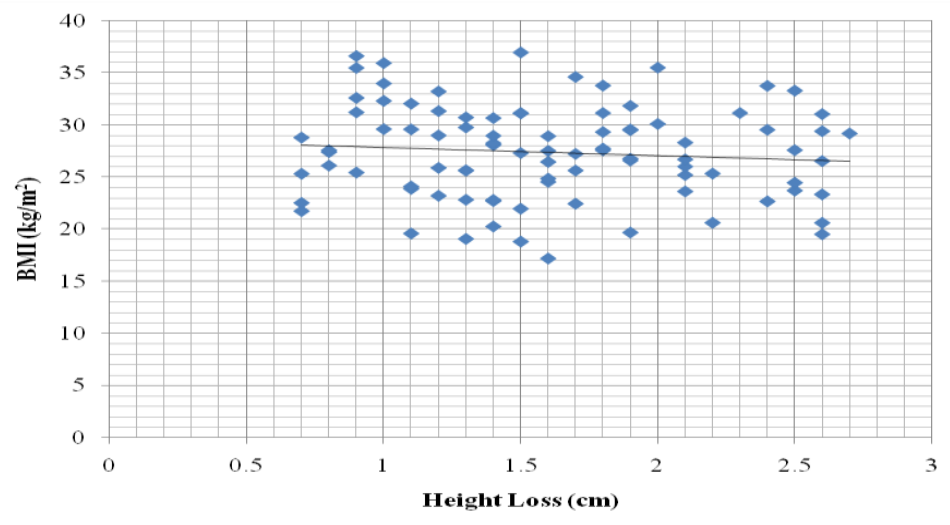

Fig4: A graph of BMI against Height Loss

The graph shows an inverse relationship between BMI and Height loss.

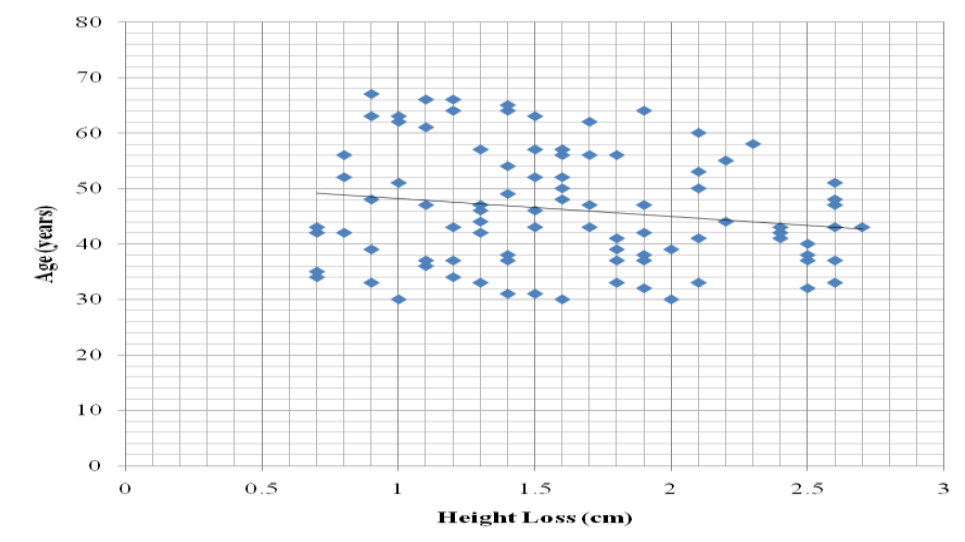

Fig5: A graph of Age against Height Loss

The graph shows an inverse relationship between age and height loss.

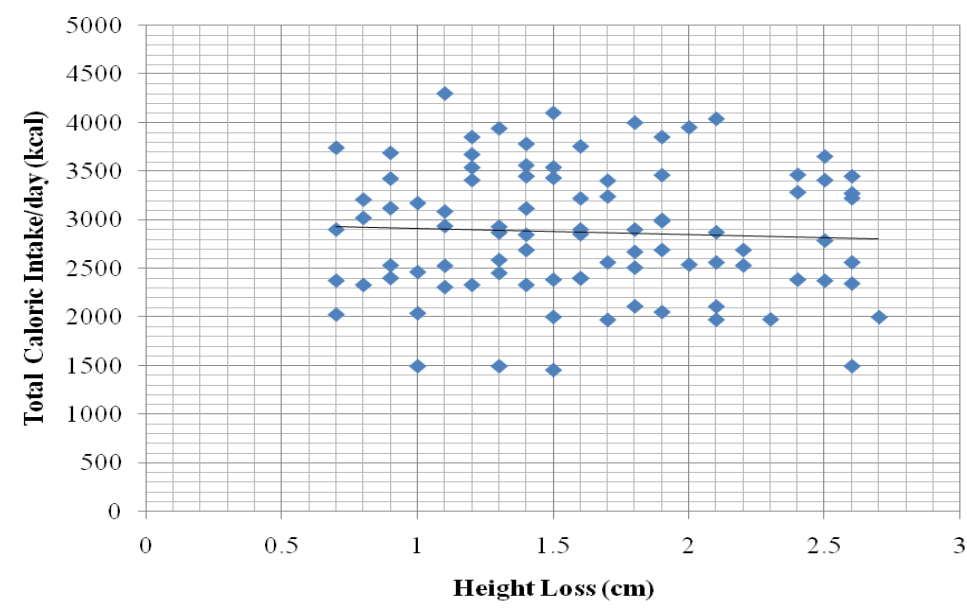

Fig6: A graph of Total Caloric Intake against Height Loss

The graph shows an inverse relationship between total caloric intake and height loss.

Upon analysis of correlation it was revealed that, parameters such as age, BMI and total caloric intake showed a negative correlation with height loss. The correlation coefficients also showed a poor fit between all parameters and height loss. The analysis further revealed that, the relationships between age, BMI and total caloric intake were not significant (Sig. 2 tailed $>0.05$ ). 
Table3: Association between Other Variables and Height Loss

\begin{tabular}{|c|c|c|}
\hline Variable & Test Analysis & p -value \\
\hline Level of Activity & \multirow{3}{*}{$\begin{array}{l}\text { Analysis of Variance } \\
\text { (One-Way ANOVA) }\end{array}$} & $<0.001$ \\
\hline Mode of Activity / Condition & & $<0.001$ \\
\hline Planned Physical Exercise & & 0.349 \\
\hline Knee Joint Pain & \multirow{3}{*}{$\begin{array}{c}\text { Independent - Sample } \\
\mathrm{T} \text { - tests Analysis }\end{array}$} & $<0.001$ \\
\hline Sex & & 0.720 \\
\hline Back Pain & & 0.255 \\
\hline
\end{tabular}

Detailed cross tabulations are shown in condition/ mode of activity and height loss Appendix 3 showed a strong association ( $\mathrm{p}$-value $<0.001$ ).

The Analysis of variance revealed the existence of an association between the variables and height loss. However the associations between type of physical exercise performed and height loss was not significant whiles that between The $\mathrm{T}$ - test analysis also revealed that sex, back pain and marital status did not have any significant association with height loss. Knee joint pain however did show a strong association with height loss.

level of activity / occupational exposure,

Table4: Correlation between Total caloric intake (kcal) and Height loss ( $\mathrm{cm}$ ).

\begin{tabular}{|c|l|l|}
\hline Parameter & & \multicolumn{1}{|c|}{ Weight Difference (Kg) } \\
\hline \multirow{3}{*}{ Total Calories } & Pearson Correlation & $.418^{* *}$ \\
\cline { 2 - 3 } & Sig. (2-tailed) & .000 \\
\cline { 2 - 3 } & $\mathrm{N}$ & 90 \\
\hline
\end{tabular}

**. Correlation is significant at the 0.01 level (2-tailed).

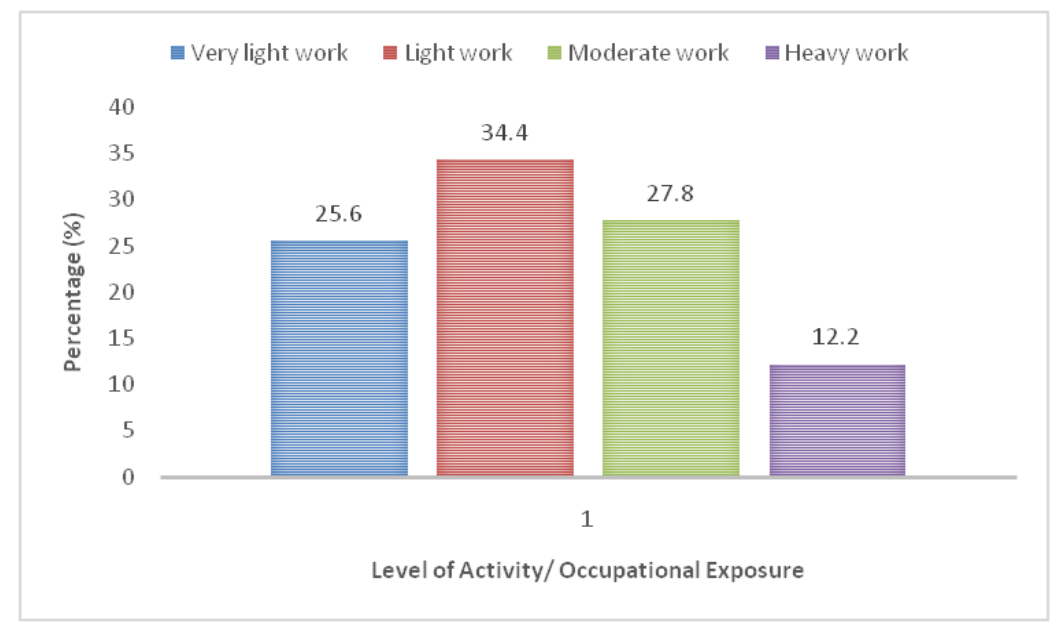

Fig7: Distribution of different levels of activity

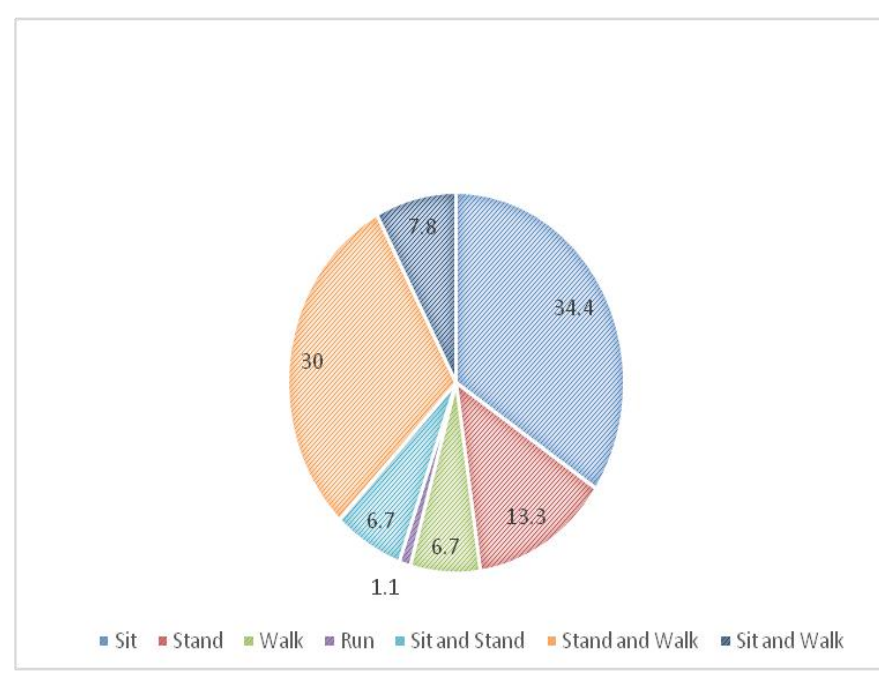

Fig 8: Distribution of different types of Physical activities 


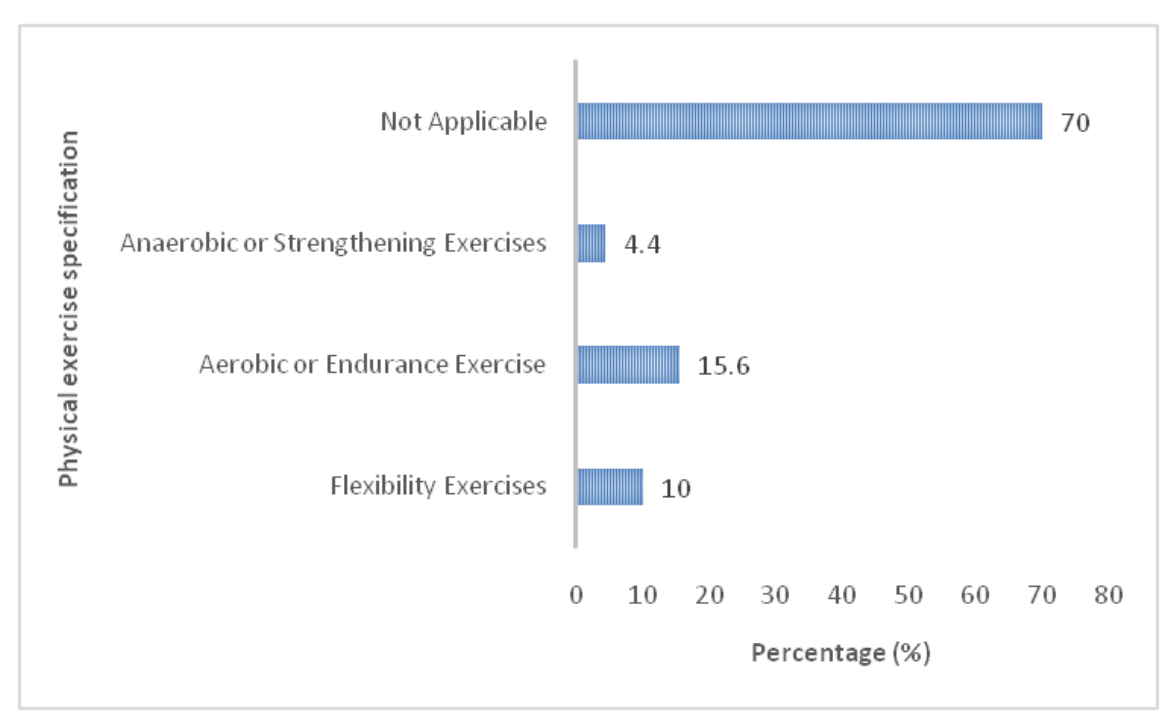

Fig9: Types of exercise participants engage in

\section{DISCUSSION}

The male respondents recorded a mean evening and morning height of $174.68 \mathrm{~cm}$ and 176.31 $\mathrm{cm}$ respectively, whiles the females recorded $165.01 \mathrm{~cm}$ and $166.60 \mathrm{~cm}$ for mean evening and morning heights respectively. Now, it is evident from the results that, the stature of an individual shows a variation at different times of the day (morning and evening). The variations which were observed to be losses in height were found to be a mean loss of $1.63 \mathrm{~cm}$ for males and 1.59 $\mathrm{cm}$ for females. These variations ranged from $0.70 \mathrm{~cm}$ to $2.70 \mathrm{~cm}$. (Buckler, 1978), also recorded a similar range from $0.80 \mathrm{~cm}$ to 2.80 $\mathrm{cm}$ in his study and further explained that, the decline in height was not always continuous throughout the day nor are measurements necessarily identical at similar times on consecutive days. This may imply that the pattern of activity during the course of the day, affects diurnal height to some extent.

Since the height of an individual rapidly begins to decrease within the first two hours after rising (Krishan \& Vij, 2007) and is said to stop six to seven hours after rising (Voss \& Bailey, 1997), comparable time periods of 6 am -8 am and 5 pm $-7 \mathrm{pm}$ were chosen to adhere, to a certain degree, the earlier statement by (Buckler, 1978). For quality assurance purposes, any subject not measured within this time range was ruled out. Generally, taller subjects recorded greater variations in stature than shorter subjects. This find is in conformity with the outcomes from previous studies and in general agreement with the statement given by Krishan and Vij (Krishan \& Vij, 2007).
Table 1 also showed a clear difference in the height loss among the sexes. Males recorded greater losses than females. The comparatively small diurnal variation in stature among the female subjects could not be properly explained by Krishan and Vij (Krishan \& Vij, 2007), however they gave a probable reason in relation to genetics and with an example stated that, females were more canalized than their male counterparts. In relation to the weights of the subjects, males are generally heavier set since they have more body muscles than fat compared to the females(Bowman \& Russell, 2001). Thus, males will show will show greater variations in height due to the body's compressive force under the influence of gravity. The T-test Analysis in Table 2 indicates that, sex played no significant role in height loss (p-value 0.720). Majority of the subjects (49.9\%) recorded height losses between $1.0 \mathrm{~cm}$ and $1.9 \mathrm{~cm}$.

Repeat measurements on individual adults were to be made not only with the same instrument, but also by the same observer and assistant to ensure accuracy and consistency in the height measurements. Voss et al (Voss, Bailey, Cumming, Wilkin, \& Betts, 1990)opined that, the ideal adult to measure would be rigid, but a living subject is of no fixed height. He further explained that, independent of diurnal variation, the posture can vary from one moment to the next, and the aim of measurement can only be to estimate an adult's mean height by making several separate observations.

The loss in height and gain in weight as indicated in Table 1 by the subjects from morning to evening resulted in a mean evening BMI of $28.49 \mathrm{~kg} / \mathrm{m}^{2}$ and mean morning BMI of $27.39 \mathrm{~kg} / \mathrm{m}^{2}$. Their mean gain in BMI from the 
morning to evening was $1.10 \mathrm{~kg} / \mathrm{m}^{2}$ and ranged from $0.56 \mathrm{~kg} / \mathrm{m}^{2}$ to $1.95 \mathrm{~kg} / \mathrm{m}^{2}$. These values clearly show how significant diurnal height losses affect the reliability of height data and this should give rise for concern, whether in the communities, clinics, and research departments. In the year 1997 and 2007, (Voss \& Bailey, 1997)(Krishan \& Vij, 2007), respectively made general statements that complied strongly with the latter statement.

A rather intriguing find was the association between BMI and height loss which according to (Shigeta, Ogawa, Venturin, Clark, \& Enciso, 2008)(Yar, 2008)was positively correlated and significant. The graph of BMI against height loss indicated an inverse relationship, where increase in BMI gave a corresponding lower decrease in stature. In logical terms on the other hand, the weight of the body which acts as a compressive load on the spine due to gravity should lead to a corresponding increase in height loss with increasing BMI. The findings of this study however showed no significant relationship between these two. A possible explanation to this may be as a result of the activities one performs during the course of the day. This acts as a confounder, since other studies that have proven the existence of this positive relationship were performed based solely on BMI and height loss under controlled laboratory conditions.

The age distribution showed that the age group of $30-50$ had the highest proportion of respondents $(15.6 \%)$. The least proportion was found in the $66-70$ years age group (3.3\%). There were more males $(57.8 \%)$ than females $(42.2 \%)$ in the study with the highest male proportion being in the $30-40$ years age group whilst the highest female proportion was found to be amongst the $41-45$ years age group. The maximum height loss was found to be more prominent amongst subjects of the $41-50$ years age group.

The negative slope in Fig 5 indicates an inverse correlation between age and height loss. Thus, as age increases the height loss of individuals decreases. In an attempt to find whether age did in fact influence height loss, Reilly and Freeman (2006) in their findings showed that, irrespective of age one loses height based on the compressive loading on the spine. In relation to this statement, the heavier free fat mass found in younger individuals could be the factor or compressive load that makes them gain greater height losses than their older counterparts.

The study revealed that, majority $(60.0 \%)$ of the respondents performed occupations that were classified under light work such as secretary, bank manager, cashier, etc. whiles the least proportion of respondents(12.2\%) performed heavy duty work such as digging, masonry, weight lifting, truck pushing, etc. It was further observed from the study that the work activities involved conditions such as sitting, walking, standing, running or a combination of any two. The results demonstrated significant occupational activity - related decreases in height (p-value <0.001) (Table 3). This clearly implies that, the activity one performs during the day plays a vital role in diurnal height variations. (Francis Smith \& Hadjipavlou, 2004); (Leivseth \& Drerup, 1998); (Ismaila \& Charles-Owaba, 2008) ;(Bourne \& Reilly, 1991) showed similar results and opined that the main cause of height loss was due to the type, condition and level of activity of any occupation one performs during the course of the day. The degree of shrinkage was related to the magnitude of compressive load or force on the spine (Eston \& Reilly, 2013). A typical example by (Adams et al., 1990)Adams et al. explained the time scale and magnitude of diurnal changes, revealing that heavy labour will have a greater effect in less time than sedentary activities.

Thirty percent (30\%) of the respondents performed planned physical exercises during the day. The type of physical exercise reduced in intensity from anaerobic, aerobic to flexibility exercises (Boutaugh, 2003). No significant relationship was observed upon analysis of the association between type of physical exercise and height loss. A high proportion of height is lost within the first 2- 3 hours of the day after rising from bed(Buckler, 1978). This loss occurs spontaneously due to the effect of gravity on an individual. After further probing of subjects it was made clear that the planned physical exercises were usually performed during this time period (2- 3 hours after rising), and may have offset to some extent the effect of the exercises on height loss (Smith, 2003).

Most respondents $(51.1 \%)$ consumed between $2000-2999 \mathrm{kcal}$ during the course of the day whilst only $4.4 \%$ of the respondents consumed 4000 - 4999 kcal. A cross tabulation between height loss and total caloric intake revealed that those who consumed between 2000 - 2999 kcal 
recorded the most height loss (Appendix 3). Fig 6 showed an inverse relationship between caloric intake and height loss. An increase in food consumption therefore should have a corresponding decrease in height loss. This relationship was not significant (2-tailed 0.619). However, a very significant association exists between weight gain by the day's end and total caloric intake for that day $(<0.001)$. It may be stipulated that, though eating leads to slight weight gain at the end of the day, it does not necessarily contribute to height loss in any way.

Equal percentages of respondents $(30 \%)$ were observed to have reported of recent back pain and knee joint pain. These percentages were not however from the same individuals. There was no significant association between height loss and back pain but a very significant association between height loss and knee joint pain was observed after an independent sample t-test. (Ismaila \& Charles-Owaba, 2008)found conclusive evidence that state otherwise. They linked spinal shrinkage to back pain and reported that the spine may be prone to injuries if the load or its frequency exceeds the tissue threshold or tolerance. This ideology may be linked to the occurrence of knee joint pain when high biomechanical force promotes thinning of the knee cartilages (Waterton et al., 2000). A possible explanation may be due to when the biomedical force for supersedes the tolerance level of the knee tissues.

In summary, the maximum height losses (2.6 $2.7 \mathrm{~cm}$ ) were found to be most prominent for subjects within the $41-50$ years age group $(57.2 \%)$, who were males $(71.4 \%)$, with BMI in the normal and obese ranges $(85.8 \%)$, who performed heavy work (85.7\%) and who consumed 2000 - $2999 \mathrm{kcal}$ per day (57.1\%). Significant associations existed between level and conditions of activity or occupation (< $0.001)$.

\section{CONCLUSION}

It has been concluded that, intra-individual variation in stature can substantially affect the reliability of height data. The average loss in height of Ghanaian subjects was $1.61 \mathrm{~cm}$. The maximum permissible shrinkage was $2.7 \mathrm{~cm}$ whiles the least was $0.7 \mathrm{~cm}$. The occupational activities performed by the respondents, acts as the major cause of diurnal variation in height, though this occurs in varying degrees due to differences in posture and conditions of the activities. Age, sex, BMI and total caloric intake influence height loss. The occurrence of knee joint pain showed a statistically significant association with height loss. This investigation alarms scientists in fields of study pertaining to measurement of height, of the accountability and significance of diurnal variations in height.

\section{REFERENCES}

[1] Adams, M., Dolan, P., Hutton, W., \& Porter, R. (1990). Diurnal changes in spinal mechanics and their clinical significance. Bone \& Joint Journal, 72(2), 266-270.

[2] Barba, C., Cavalli-Sforza, T., Cutter, J., \& Darnton-Hill, I. (2004). Appropriate body-mass index for Asian populations and its implications for policy and intervention strategies. The lancet, 363(9403), 157.

[3] Berecki-Gisolf, J., Spallek, M., Hockey, R., \& Dobson, A. (2010). Height loss in elderly women is preceded by osteoporosis and is associated with digestive problems and urinary incontinence. Osteoporosis international, 21(3), 479-485.

[4] Bourne, N., \& Reilly, T. (1991). Effect of a weightlifting belt on spinal shrinkage. British journal of sports medicine, 25(4), 209-212.

[5] Boutaugh, M. L. (2003). Arthritis Foundation community-based physical activity programs: Effectiveness and implementation issues. Arthritis Care \& Research, 49(3), 463-470.

[6] Bowman, B., \& Russell, R. (2001). Present knowledge in nutrition, International Life Sciences Institute: ILSI Press, Washington DC.

[7] Briot, K., Legrand, E., Pouchain, D., Monnier, S., \& Roux, C. (2010). Accuracy of patientreported height loss and risk factors for height loss among postmenopausal women. Canadian Medical Association Journal, 182(6), 558-562.

[8] Buckler, J. (1978). Variations in height throughout the day. Archives of disease in childhood, 53(9), 762.

[9] Dowzer, C., Reilly, T., \& Cable, N. (1998). Effects of deep and shallow water running on spinal shrinkage. British journal of sports medicine, 32(1), 44-48.

[10] Eston, R., \& Reilly, T. (2013). Kinanthropometry and exercise physiology laboratory manual: tests, procedures and data: volume two: physiology: Routledge.

[11] Francis Smith, M., \& Hadjipavlou, A. (2004). Spine height and disc height changes as the effect of hyperextension using stadiometry and MRI. Published by the Residents and Faculty of the Department of Orthopaedics, The University of Iowa, 24, 65. 
[12] Ismaila, S., \& Charles-Owaba, O. (2008). Determination of the highest permissible spinal shrinkage. Australian Journal of Basic and Applied Sciences, 2(4), 872-875.

[13] Karakida, O., Ueda, H., Ueda, M., \& Miyasaka, T. (2003). Diurnal T2 value changes in the lumbar intervertebral discs. Clinical radiology, 58(5), 389-392.

[14] Krishan, K., \& Vij, K. (2007). Diurnal variation of stature in three adults and one child. Anthropologist, 9(2), 113-117.

[15] Leivseth, G., \& Drerup, B. (1998). Spinal shrinkage during work in a sitting posture compared to work in a standing posture. Occupational Health and Industrial Medicine, 1(35), 32.

[16] Park, C. O. (1997). Diurnal variation in lumbar MRI. Yonsei medical journal, 38(1), 8-18.

[17] Rodacki, A. L. F., Fowler, N. E., Provensi, C. L. G., Rodacki, C. d. L. N., \& Dezan, V. H. (2005). Body mass as a factor in stature change. Clinical Biomechanics, 20(8), 799-805.

[18] Shigeta, Y., Ogawa, T., Venturin, J., Clark, G. T., \& Enciso, R. (2008). The influence of age and BMI on intervertebral disc height and oropharyngeal airway in Japanese men and women. International Journal of Computer Assisted Radiology and Surgery, 3(1-2), 97103.

[19] Siklar, Z., Sanli, E., Dallar, Y., \& Tanyer, G. (2005). Diurnal variation of height in children. Pediatrics International, 47(6), 645-648.
[20] Smith, F. (2003). Measurement of diurnal variation in intervertebral disc height in normal individuals: a study comparing supine with erect MRI. Radiological Society of North America (RSNA).

[21] Sorkin, J. D., Muller, D. C., \& Andres, R. (1999). Longitudinal change in height of men and women: implications for interpretation of the body mass index: the Baltimore Longitudinal Study of Aging. American journal of epidemiology, 150(9), 969-977.

[22] Voss, L., \& Bailey, B. (1997). Diurnal variation in stature: is stretching the answer? Archives of disease in childhood, 77(4), 319-322.

[23] Voss, L., Bailey, B., Cumming, K., Wilkin, T., \& Betts, P. (1990). The reliability of height measurement (the Wessex Growth Study). Archives of Disease in Childhood, 65(12), 1340-1344.

[24] Waterton, J. C., Solloway, S., Foster, J. E., Keen, M. C., Gandy, S., Middleton, B. J., . . . Taylor, C. J. (2000). Diurnal variation in the femoral articular cartilage of the knee in young adult humans. Magnetic resonance in medicine, 43(1), 126-132.

[25] WHITE III, A. A., \& Gordon, S. L. (1982). Synopsis: workshop on idiopathic low-back pain. Spine, 7(2), 141-149.

[26] Yar, T. (2008). Using "spinal shrinkage" as a trigger for motivating students to learn about obesity and adopt a healthy lifestyle. Advances in physiology education, 32(3), 237-241

Citation: Frederick Vuvor, Obed Harrison. A Study of the Diurnal Height Changes Among Sample of Adults Aged Thirty Years and above in Ghana, ARC Journal of Diabetes and Endocrinology.2017; 3(1):24-33. doi:dx.doi.org/10.20431/2455-5983.0301004.

Copyright: () 2017 Authors. This is an open-access article distributed under the terms of the Creative Commons Attribution License, which permits unrestricted use, distribution, and reproduction in any medium, provided the original author and source are credited. 